\title{
曲げおよびねじりを受けるクラックを有する帯板の 混合境界值問題の解析
}

\author{
A MIXED BOUNDARY VALUE PROBLEMS OF A STRIP WITH A CRACK UNDER \\ THE CONCENTRATED BENDING AND TORSIONAL MOMENTS
}

\author{
長谷部宣男* ·三輪昌 弘**.中村卓 次*** \\ By Norio HASEBE, Masahiro MIWA and Takuji NAKAMURA
}

\begin{abstract}
The mixed boundary value problem of the thin plate is analyzed for a strip under concentrated bending and torsion. The strip has a part of the boundary where the displacement is constrained, and a crack initiating from an end of the constrained part. A rational mapping function which maps the strip with a crack into a unit circle and the complex stress functions for the deflection are used. The first derivative of the complex stress function is obtained in a closed form without integral term. The stress distributions before and after crack initiation, and the stress intensity factors of the thin plate for the bending and torsional modes are obtained from short to long cracks. The stress intensity factors are compared with those of other strips which are different in the constrained degree of the strip edge, and the effect of Poisson's ratio is studied.

Keywords : thin plate bending, mixed boundary, mapping function, crack, strip
\end{abstract}

\section{1. まえがき}

古典理論による薄板の曲げの問題は, 多く解析されて いる.しかし，その混合境界値問題，さらにはクラック と連成した問題の解析は多くないようである ${ }^{11}$. 外力境 界值問題としてのクラックの問題に注目しても, 平面弾 性のクラックの問題ほどには解析されていない2) 4). 有 理写像関数を用いた薄板の混合境界値問題の一般解法は 文献 1) で報告した。写像関数を導入することによって 任意の形状の解析が可能になり, さらに, 写像関数とし て有理関数を用いることにより, 積分方程式を解くこと なく, 閉じた解が得られる. したがって, 有理写像関数 の表わす形状に対して厳密解が得られる. 本論文で用い る分数式の和の有理写像関数は, 帯板の形状のように数 学的に対数特異を有する関数に対しても精度よく作ら $れ^{5) \sim 81}$, 比較的任意の形状の写像関数を作ることができ る. 応力拡大係数を求めるクラックの問題にも適用でき $3^{(1,6), 7), 9), 10)}$. 平面弾性混合境界値問題として, 面内の

* 正会員 工博 名古屋工業大学教授 工学部社会開発工 学科 ( 466 名古屋市昭和区御器所町)

** 正会員 工修 東海旅客鉄道 ( ₹450 名古屋市中村区名駅 1 丁目)

*** 正会員 工修 名古屋工業大学助教授 工学部社会開発 工学科
引張りや偶力が作用した帯板の変位拘束端の片側からク

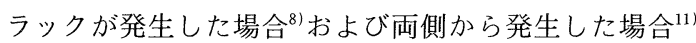
の解析は行われているが，この種の形状の薄板の混合境 界値問題の解析解は多くないようである. 本論文で解析 する帯板の縁が拘束された形状は，たとえば，面外曲げ やねじりを受けるI形断面のフランジを変位拘束部分と 考え, フランジのあるところとないところの境の部分に 注目し, さらに, 変位拘束端の応力集中によってクラッ クが発生した状態などのモデルに相当している．荷重と して集中曲げやねじりモーメントを考える。このとき複 素応力関数中の荷重項は Plemelj 関数を含む積分形で 与えられる。しかし，この積分は容易ではないが本論文 に示すように，この荷重項の 1 次導関数が得られる. し たがって，複素応力関数の 1 次導関数が積分項を含まな い形で得られる。これによって, 応力成分は数值積分を することなく容易に計算される．短いクラックから長い クラックまで応力拡大係数を精度よく得るために，写像 の対応点を変えた 2 種類の写像関数が用いられる.

\section{2. 写像 関 数}

Fig. 1 に示すクラックを有する帯状領域を, 単位円内 に等角写像する関数は, Schwarz-Christoffel の変換公 式を用いて表わすことができる。この関数は無理関数で 


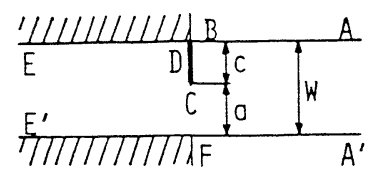

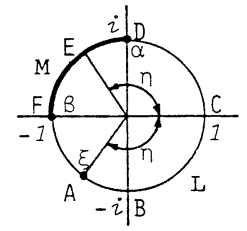

(a)

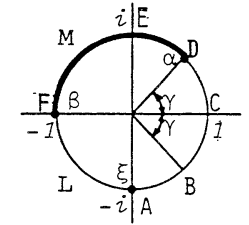

(b)
Fig. 1 Strip region with a crack and associated unit circles.

あるため,この式から分数式の和の形の有理写像関数を 作る. しかし, この有理写像関数で表わされる形状は, クラック先端で小さな丸味を有する. クラックが非常に 短いときには, クラック長に比してクラック先端の丸味 が十分小さくないとクラックとみなしにくく, 応力拡大 係数を精度よく求めることはできない. また，クラック が十分長くなり帯板の幅に近いときにも正確な形状を表 わしている必要がある。このため本論文では, Fig. 1 (a), (b) に示すように, $z$ 平面と $\zeta$ 平面の対応する点

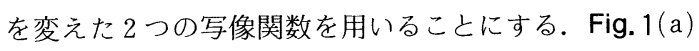
に示す写像関数は

$$
z=\omega(\zeta)=K_{1} \int \frac{\zeta-1}{\left(\zeta^{2}+1\right)^{0.5}\left(\zeta-e^{-i \eta}\right)\left(\zeta-e^{i \eta}\right)} d \zeta
$$

Fig. 1(b) のそれは

$$
z=\omega(\zeta)=K_{2} \int \frac{\zeta-1}{\left(\zeta^{2}+1\right)\left(\zeta-e^{-i \gamma}\right)^{0.5}\left(\zeta-e^{i \gamma}\right)^{0.5}} d \zeta
$$

と表わされる. 式 ( 1 ), ( 2 ) 中の $\eta$, および $\gamma$ はクラッ クの長さに関するパラメーターで, 同一のクラック長に 対して $\eta+\gamma=\pi$ の関係がある. 式 (2)において, $\gamma$ $=0$ とすると, クラックのない帯状の形状となる. 式 ( 1 )，(2) の係数 $K_{1}, K_{2}$ は带板の幅がそれぞれ $W$ に なるように定められる. 式 (1) や（2）より分数式の 和の形の有理写像関数を作る. 式 ( 2 ) の場合について, その概略は文献 8) に, また, 他の形状について, 一般 的方法が文献 6)，9）に述べてあるので，ここでは，そ の要点のみを述べる. 式 $(2)$ の被積分関数を収束の遅 い項と速い項に分解すると

$$
\begin{aligned}
z / K_{2}= & \frac{A}{2} \int \frac{d \zeta}{1-i \zeta}+\frac{A}{2} \int \frac{d \zeta}{1+i \zeta}+\int \frac{C}{\left(e^{-i \gamma}-\zeta\right)^{0.5}} d \zeta \\
& +\int \frac{D}{\left(e^{i \gamma}-\zeta\right)^{0.5}} d \zeta
\end{aligned}
$$

$$
\begin{aligned}
& +\int\left\{\frac{1-\zeta}{\left(1+\zeta^{2}\right)\left(e^{-i \gamma}-\zeta\right)^{0.5}\left(e^{i \gamma}-\zeta\right)^{0.5}}\right. \\
& \left.-\frac{A}{1+\zeta^{2}}-\frac{C}{\left(e^{-i \gamma}-\zeta\right)^{0.5}}-\frac{D}{\left(e^{i \gamma}-\zeta\right)^{0.5}}\right\} d \zeta
\end{aligned}
$$

と表わされる. 式 (3) 右辺第 1 項から第 4 項までが収 束の遅い項で, 第 5 項の積分項は収束の速い項である. $A, C, D$ は分解したときの係数で容易に求められる. 式 (3) のそれぞれの項に対して, 分数式の和の形の関 数を作る. 最終的に

$$
\int \frac{d \zeta}{1-i \zeta}=i \ln (1-i \zeta)=-i \sum_{j=1}^{14}\left(\frac{C_{j}}{1-i \beta_{j} \zeta}-C_{j}\right)
$$

$$
\begin{aligned}
\int \frac{d \zeta}{\left(e^{-i \gamma}-\zeta\right)^{0.5}} & =-2 e^{-0.5 i \gamma}\left(1-e^{i \gamma \zeta)^{0.5}}\right. \\
& =-2 e^{-0.5 i \gamma}\left[1+\sum_{j=1}^{12}\left(\frac{-F_{j}}{1-e^{i \gamma} \alpha_{j} \zeta}-+F_{j}\right)\right]
\end{aligned}
$$

式 (3) の最終積分項 $=\sum_{j=1}^{m} \frac{G_{j} \gamma_{j} \zeta}{1-\gamma_{j} \zeta}$

となる. 式 (3) の第 2,4 項は, それぞれ式 (4), (5) の $i$ の代わりに $-i$ を代入して得られる. 式 (4), （5），(6)の作り方は文献 5)，9），7）に述べてあるので, ここでは省略する. 最終的に式（3）は次式で表わされ る.

$$
\begin{aligned}
z= & \frac{-i A}{2} \sum_{j=1}^{14}\left(\frac{C_{j}}{1-i \beta_{j} \zeta}-C_{j}\right)+\frac{i A}{2} \sum_{j=1}^{14}\left(\frac{C_{j}}{1+i \beta_{j} \zeta}-C_{j}\right) \\
& -2 C e^{-0.5 i \gamma}\left[1+\sum_{j=1}^{12}\left(\frac{-F_{j}}{1-e^{i \gamma} \alpha_{j} \zeta}+F_{j}\right)\right] \\
& -2 D e^{0.5 i \gamma}\left[1+\sum_{j=1}^{12}\left(\frac{-F_{j}}{1-e^{-i \gamma} \alpha_{j} \zeta}+F_{j}\right)\right]+\sum_{j=1}^{m} \frac{G_{j} \gamma_{j} \zeta}{1-\gamma_{j} \zeta}
\end{aligned}
$$

式（7）を整理すると, 次式の形に表わされる.

$$
z=\omega(\zeta)=\sum_{k=1}^{n} \frac{E_{k}}{\zeta_{k}-\zeta}+E_{-1}
$$

式 $(7)$ の場合, $n=52+m$ となる. $m$ の值は, 本論 文の場合, $m=10 \sim 18$ の值が用いられる. 式 (1)の 場合も全く同様にして式（8）の形に作られる. 式 (1) をもとにして作った写像関数の式（8）の表わすクラッ ク先端の曲率半径 $\rho$ は, クラックの長さが $0.01 \leqq C / W$ $\leqq 0.8$ で, $\rho / W=10^{-9} \sim 10^{-12}$ となる. また, 式 (2) をもとにして作った写像関数の式（8）の表わすクラッ ク先端の曲率半径 $\rho$ は, $0.2 \leqq C / W \leqq 0.95$ で $\rho / W=$ $10^{-8} \sim 10^{-10}$ となり十分小さい. したがって, クラック の短い場合には, 式（1）に基づいた式（8）を，クラッ クの長い場合には，式（2）に基づいた式（8）を用い ることにより, 短いクラックから長いクラックまでの応 力拡大係数を精度よく求めることができる. また式 (8) 
は, 有理関数のため, 帯板の長さは有限長になる.

\section{3. 解析方法}

式（8）の形の有理写像関数を用いて, 外力境界 $(L$ とよぶ）と変位境界 $(M$ とよぶ）が，それぞれ 1 か所 ある場合の薄板の曲げの混合境界值問題の一般解は, 文 献1）に報告した。したがって，ここではまずその一般 解の式を示し，さらに本論文で扱う集中曲げモーメント やねじりモーメントの場合の荷重項を導く.

単位円内で正則な，たわみに関する複素関数を， $\phi(\zeta), \phi(\zeta)$ とすると, $\phi(\zeta)$ の般解は

$$
\begin{aligned}
& \phi(\zeta)=H(\zeta)+\frac{\chi(\zeta)}{\chi} \sum_{k=1}^{n} \frac{\bar{A}_{k} B_{k}}{\chi\left(\zeta_{k}\right)\left(\zeta_{k}-\zeta\right)} \cdots \cdots \cdots \cdots \cdots(9) \\
& H(\zeta)=-\frac{M(\zeta)}{\chi}+\frac{(\chi+1) \chi(\zeta)}{2 \pi i \chi} \int_{M} \frac{M(\sigma)}{\chi(\sigma)(\sigma-\zeta)} d \sigma \cdots(10) \\
& M(\zeta)=\frac{1}{2 \pi i} \int_{L+M} \frac{f(\sigma)}{\sigma-\zeta} d \sigma \cdots \ldots \ldots \ldots \ldots \ldots \ldots \cdots \cdots(11) \\
& f(\sigma)=\left\{\begin{array}{lr}
\frac{\partial w}{\partial x}+i \frac{\partial w}{\partial y} & \text { on } M \\
\frac{1}{D(1-\nu)} \int\left[m(s)+i \int p(s) d s\right] d z & \text { on } L
\end{array}\right.
\end{aligned}
$$

と表わされる.ここに， $\chi(\zeta)$ は Plemelj 関数で

$$
\chi(\zeta)=(\zeta-\alpha)^{1-\lambda}(\zeta-\beta)^{\lambda}, \quad \lambda=0.5-i \frac{\ln x}{2 \pi},
$$

$\alpha, \beta$ は, $L$ と $M$ の境界の座標を表わす (Fig. 1 参照). $\bar{A}_{k}=\phi^{\prime}\left(\zeta_{k}^{\prime}\right), \quad \zeta_{k}^{\prime} \equiv 1 / \bar{\zeta}_{k}, \quad B_{k}=E_{k} / \overline{\omega^{\prime}\left(\zeta_{k}^{\prime}\right)} \cdots \cdots \cdots(13)$
$\varkappa=(3+\nu) /(1-\nu), \quad \nu:$ ポアソン比, $w:$ たわみ, $D:$ 曲げ剛さ,

$\sigma$ は単位円上の $\zeta$ を表わす. $m(s), p(s)$ は, 境界上 の単位長さ当たりの曲げモーメントおよび置換せん断力 である. $s$ は任意点を起点として, 境界に沿う長さを示 す.

また， $\psi(\zeta)$ は境界上で自由境界が存在する場合には, 解析接続より

$$
\phi(\zeta)=\varkappa \bar{\phi}(1 / \zeta)-\frac{\bar{\omega}(1 / \zeta)}{\omega^{\prime}(\zeta)} \phi^{\prime}(\zeta)
$$

と与えられる.

本論文では, Fig. 1(a), (b) に示すように, $\zeta=\xi の ~$ 点で集中曲げモーメント $M_{0}$ やねじりモーメント $T_{0}$ が 作用し, 境界の一部が固定された場合を考える.この場 合, 式 (12) の $f(\sigma)$ は

$$
\begin{aligned}
f(\sigma) & =\frac{i M_{0}+T_{0}}{D(1-\nu)} \\
& =0 \\
& =0
\end{aligned}
$$$$
\begin{aligned}
& \text { on } \widehat{\mathrm{ABCD}} \\
& \text { on } \widehat{\mathrm{DEF}} \\
& \text { on } \overparen{\mathrm{FA}}
\end{aligned}
$$

となる.この $f(\sigma)$ を式 (11), さらに式 (10) に代入す ると

$$
\begin{aligned}
H(\zeta)= & \frac{-M_{0}+i T_{0}}{2 \pi x D(1-\nu)} \ln \frac{\zeta-\alpha}{\zeta-\xi} \\
& +\frac{(x+1) \chi(\zeta)}{2 \pi i \varkappa} \int_{\alpha}^{\beta} \frac{\left(M_{0}-i T_{0}\right)}{2 \pi D(1-\nu)} \\
& \cdot \frac{\ln [(\sigma-\alpha) /(\sigma-\xi)]}{\chi(\sigma)(\sigma-\zeta)} d \sigma \cdots \cdots
\end{aligned}
$$

となる. 式 (16) の積分は難しい。しかし, その 1 次導 関数 $H^{\prime}(\zeta)$ は，付録の方法で，積分を含まない形で求め られる. したがって, 式 $(9)$ より $\phi^{\prime}(\zeta)$ が求められ, 式 $(14)$ の $\phi(\zeta)$ とともに, 曲げモーメントやねじりモ一 メント，せん断力などの応力成分は容易に計算できる.

クラック発生後の D 付近は (Fig. 1), 隅角部の角度 $90^{\circ}$ で，一辺固定，一辺自由の場合の応力の order の振 舞いをする ${ }^{13)}$. 本論文の場合は, Plemelj 関数と写像関 数によって, その応力の振舞いが表わされ, 応力関数の 中に, $90^{\circ}$ の場合の order が陽には現われていない.

\section{4. 応力分布}

曲げモーメントやねじりモーメントの分布例を, Fig. 2〜 5 に示す. $M_{r}, M_{\theta}$ は，それぞれ境界の法線およ び接線方向の曲げモーメントを,また, $M_{r \theta}$ はねじりモー メントを表わす.したがって, 図中のたとえば $y=0$, -1.0 上の $M_{\theta}$ は $M_{x}$ に, $M_{r \theta}$ は $M_{x y}$ に, クラック面の $M_{\theta}$ は $M_{y}$ にあたる. 応力分布は, $\nu=0.25$ で, それぞ れの図の, 上にクラック発生前, 下に発生後 $(C / W=0.4)$ の分布を示す。また，固定部分 $M$ 上の曲げモーメント 等の成分の間には $M_{r \theta}=0, M_{\theta} / M_{r}=\nu$ の関係がある ${ }^{1)}$.

Fig. 2, 3 は, 帯板の先端に集中曲げモーメント $M_{0}$ が作 用した場合である. クラック発生前, 変位拘束端の L 側 に大きな $M_{\theta}\left(=M_{x}\right)$ の集中があり，クラック発生の可 能性が，また， $\mathrm{M}$ 側に $M_{r}\left(=M_{y}\right)$ の集中がみられ，拘 束部に剶離発生の可能性がある.変位拘束部の, 曲げモ一 メント分布に及ぼす影響範囲を図から知ることができ る.

Fig. 4, 5 には，帯板の先端に集中ねじりモーメントが 作用した場合の応力分布を示す。

クラックや剥離発生の可能性, 変位拘束部の影響等を 知ることができる.

\section{5. 応力拡大係数}

曲げおよびねじりのモードに関する応力拡大係数を求 める. クラック先端付近の曲げモーメントやねじりモー メントは次式で表わされる ${ }^{91,14)}$.

$$
\begin{aligned}
& m_{x}+m_{y}=\frac{2}{\sqrt{2 r}}\left(k_{B} \cos \frac{\theta}{2}-k_{s} \sin \frac{\theta}{2}\right) \\
& m_{y}-m_{x}+2 i m_{x y}=\frac{1}{2(1+\nu) \sqrt{2 r}}\left\{\left[(7+\nu) k_{B}\right.\right.
\end{aligned}
$$



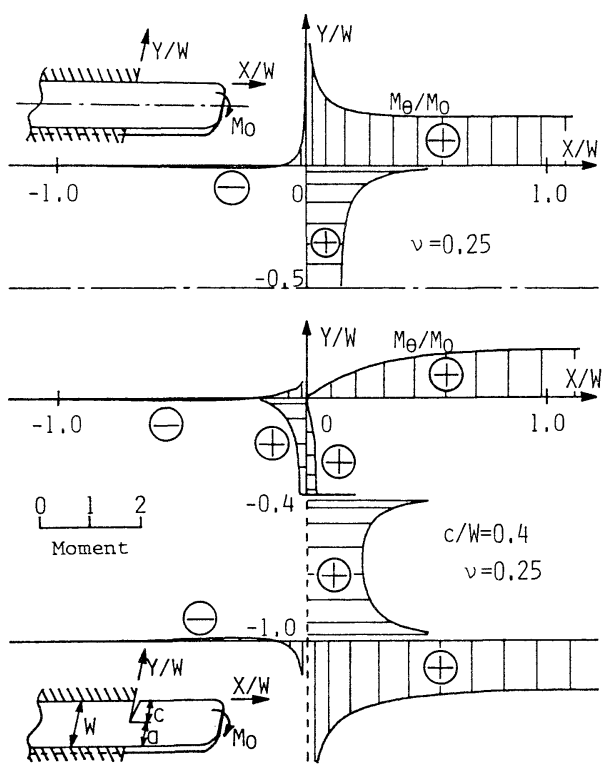

Fig. 2 Stress distribution $\left(M_{\theta}\right)$ before and after crack initiation under a concentrated bending moment.
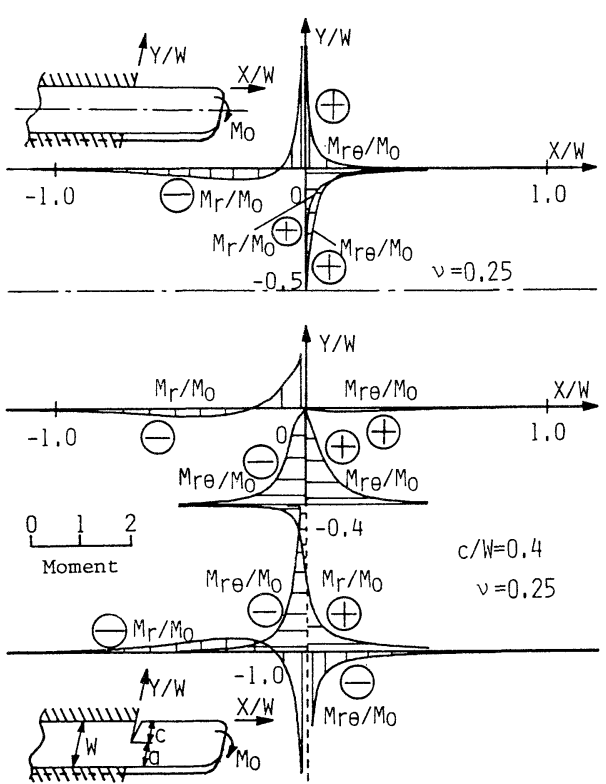

Fig. 3 Stress distribution $\left(\boldsymbol{M}_{r}, \boldsymbol{M}_{r \theta}\right)$ before and after crack initiation under a concentrated bending moment.

$$
\begin{aligned}
& \left.+i(5+3 \nu) k_{S}\right] e^{-\frac{i \theta}{2}} \\
& \left.+(1-\nu)\left(k_{B}-i k_{S}\right) e^{-\frac{5 i \theta}{2}}\right\}
\end{aligned}
$$

ここに, $r$ はクラック先端からの距離, $\theta$ はクラックの 方向から測った角度である。 $k_{B}, k_{s}$ が曲げおよびねじ りに関する応力拡大係数である. これらは, 応力関数 $\phi(\zeta)$ から次式によって計算される.
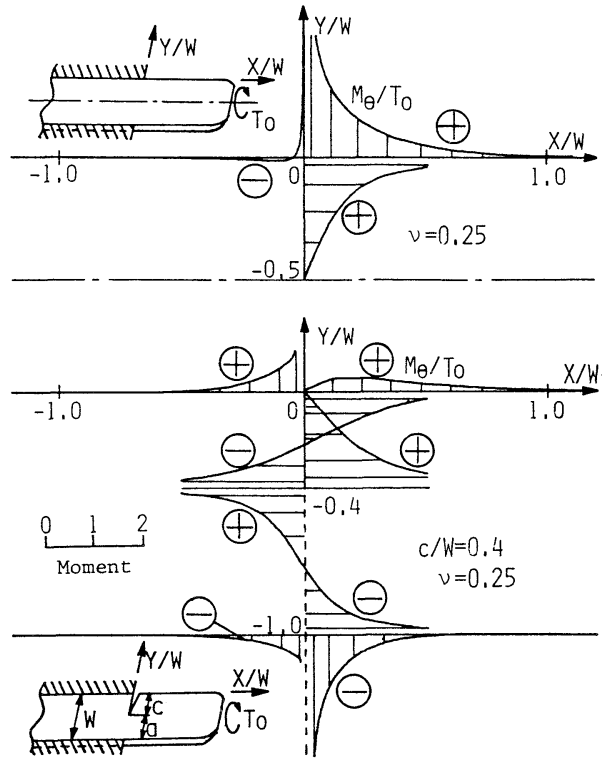

Fig. 4 Stress distribution $\left(M_{\theta}\right)$ before and after crack initiation under a concentrated torsional moment.
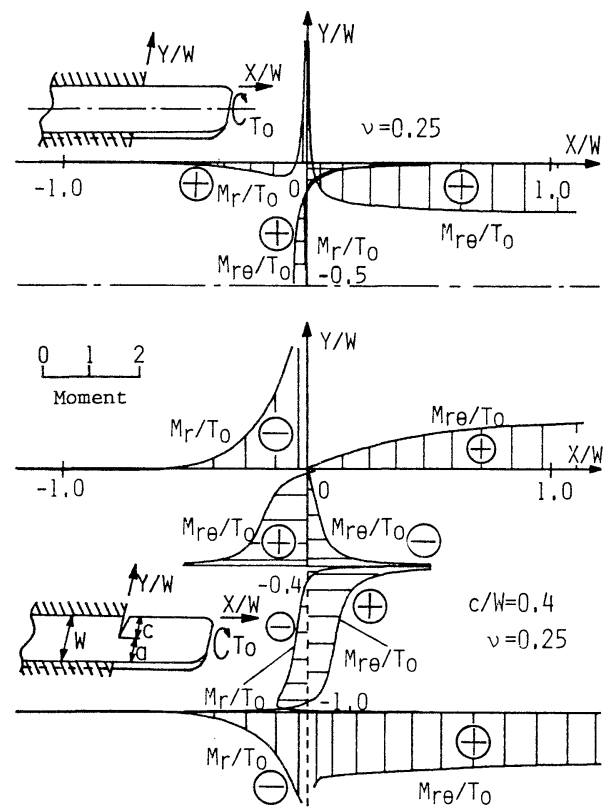

Fig. 5 Stress distribution $\left(\boldsymbol{M}_{r}, \boldsymbol{M}_{r \boldsymbol{\theta}}\right)$ before and after crack initiation under a concentrated torsional moment.

$$
k_{B}-i k_{S}=-2 D(1+\nu) e^{-i \delta / 2} \phi^{\prime}\left(\zeta_{0}\right) / \sqrt{\omega^{\prime \prime}\left(\zeta_{0}\right)}
$$

ここに, $\delta$ はクラックと $x$ 軸のなす角, $\zeta_{0}$ はクラック 先端に対応する単位円上の座標で, 今の場合 $\delta=-\pi / 2$, $\zeta_{0}=1$ である. 本論文では, 次式で定義される無次元化 した応力拡大係数 $F_{B}, F_{S}$ を用いる. 


$$
F_{B}+i F_{S}=\left(k_{B}+i k_{S}\right) \frac{3+\nu}{1+\nu} \frac{\sqrt{a}}{\left\{\begin{array}{c}
M_{0} \\
T_{0}
\end{array}\right\}}
$$

ここに，aはリガメントの長さを表わす (Fig.1参照).

Fig. 6 には，集中曲げモーメントが作用した場合の本 論文のクラック (Case 1), 半無限板と帯板の接合部に 発生したクラック (10) (Case 2 ), 帯板に発生したクラッ $ク^{7)}$ (Case 3 ) の $F_{B}, F_{s}$ を, Table 1 には Case 1 の $F_{B}, F_{S}$ を示す. Fig. 6 より, 帯板の側面の拘束の違いに

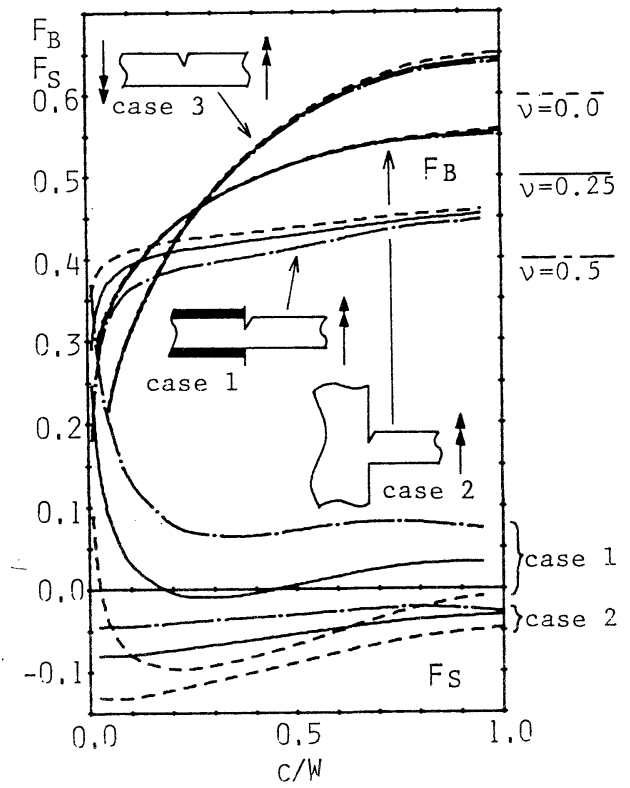

Fig. 6 Nondimensional stress intensity factors under a concentrated bending moment.
よって,クラックがどんな影響を受けるかを知ることが できる. Case 1 は, Case 2, 3 に比ベポアソン比 $\nu$ の影 響をよく受けていることがわかる. $C / W$ が小さいとき， $F_{B}$ の大きさは，大きい方から Case $1>$ Case $2>$ Case 3 の順にあり， $C / W$ が大きくなると，その大きさの順は 逆になる。この理由は， $C / W$ が小さいときは，変位拘 束部や接合部の応力集中の影響が大きく，拘束条件が強 いほど $F_{B}$ 值が大きいと思われる，逆に， $C / W$ が大き くなると, クラックが開きやすい条件の方が $F_{B}$ 值が大 きくなり， $F_{B}$ の大きさの順が逆になるものと思われる.

Fig. 7, Table 2 には，集中㸚じりモーメントが作用 した場合の $F_{B}, F_{S}$ 值を示す.

\section{6. 結 語}

集中曲げおよびねじりモーメントが作用する場合の荷 重項 $H(\zeta)$ の 1 次導関数が求められたので, 複素応力関 数の 1 次導関数 $\phi^{\prime}(\zeta)$ が，積分を含まない閉じた形で求 められた。したがって，曲げモーメント等の応力成分は 容易に計算される。これらの応力成分は，式（8）の表 わす形状に対して厳密解である. 式 (1)，（2）から作っ た式（8）の写像関数を用いたことにより，短いクラッ クから長いクラックまでの応力拡大係数が精度よく求め られた. Fig. 6, 7 より，ポアンン比の応力拡大係数に及 ぼす影響, 帯縁の変位拘束の度合が応力拡大係数に及ぼ す影響を知ることができた. Plemelj 関数のパラメー 夕ー $\alpha, \beta$ を変えることによって, 拘束部分の位置を変 えることができる.また写像関数を変えることによって， たとえば帯板にクラックが斜めに生じた場合の解析もで きる。

Table 1 Nondimensional stress intensity factors under a concentrated bending moment.

\begin{tabular}{|l|rrr|rrr|}
\hline & \multicolumn{3}{|c|}{$F_{B}$} & \multicolumn{3}{c|}{$F_{S}$} \\
\cline { 2 - 7 },$c / W$ & $v=0.0$ & $v=0.25$ & $v=0.5$ & $v=0.0$ & $v=0.25$ & $v=0.5$ \\
\hline 0.010 & 0.356 & 0.290 & 0.181 & 0.088 & 0.246 & 0.369 \\
0.025 & 0.382 & 0.341 & 0.271 & 0.007 & 0.152 & 0.279 \\
0.050 & 0.397 & 0.371 & 0.324 & -0.044 & 0.085 & 0.202 \\
0.100 & 0.409 & 0.392 & 0.362 & -0.081 & 0.030 & 0.131 \\
0.200 & 0.421 & 0.408 & 0.385 & -0.097 & -0.005 & 0.078 \\
0.300 & 0.427 & 0.415 & 0.395 & -0.092 & -0.010 & 0.065 \\
0.400 & 0.432 & 0.422 & 0.403 & -0.081 & -0.005 & 0.065 \\
0.500 & 0.438 & 0.428 & 0.412 & -0.067 & 0.005 & 0.071 \\
0.600 & 0.443 & 0.435 & 0.422 & -0.051 & 0.015 & 0.078 \\
0.700 & 0.449 & 0.441 & 0.432 & -0.035 & 0.024 & 0.081 \\
0.800 & 0.454 & 0.477 & 0.440 & -0.022 & 0.030 & 0.080 \\
0.900 & 0.457 & 0.451 & 0.444 & -0.012 & 0.032 & 0.075 \\
0.095 & 0.460 & 0.454 & 0.447 & -0.009 & 0.032 & 0.073 \\
\hline
\end{tabular}


付

録

式 (16) の積分項の変形を行う. Fig. 8 を参照して線 分 $\xi, \alpha, \beta(=-1$, 今の場合) を囲む次の周回積分を 考える.

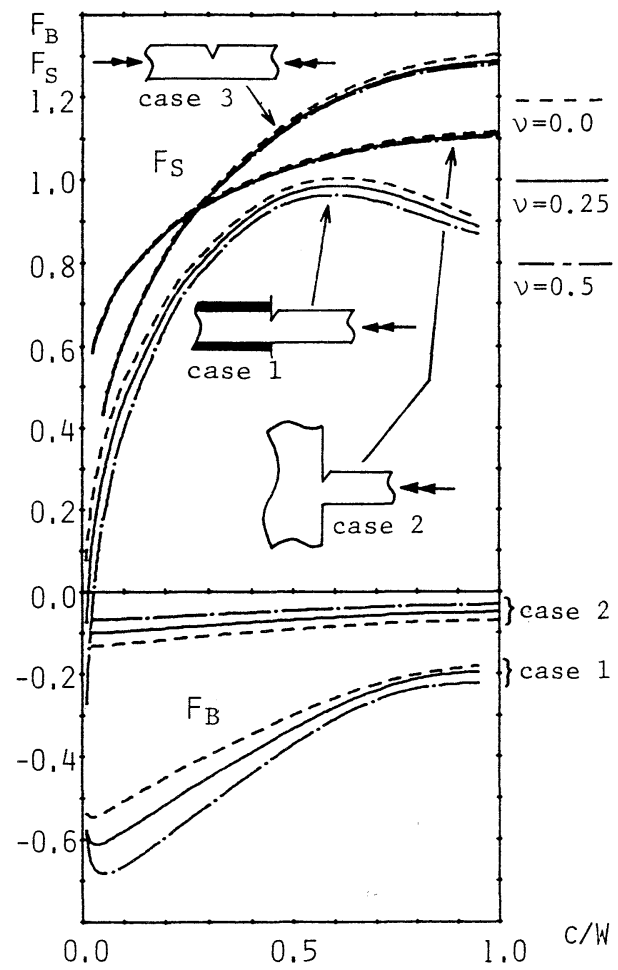

Fig. 7 Nondimensional stress intensity factors under a concentrated torsional moment.

$$
\begin{aligned}
& \frac{1}{2 \pi i} \int_{\xi}^{\alpha}[]^{+} \frac{d \sigma}{\sigma-\zeta}+\frac{1}{2 \pi i} \int_{\alpha}^{\beta}[]^{+} \frac{d \sigma}{\sigma-\zeta} \\
& +\frac{1}{2 \pi i} \int_{\beta}^{\alpha}[]^{-} \frac{d \sigma}{\sigma-\zeta}+\frac{1}{2 \pi i} \int_{\alpha}^{\xi}[]^{-} \frac{d \sigma}{\sigma-\zeta} \\
& =\frac{1}{2 \pi i} \oint[] \frac{d \sigma}{\sigma-\zeta}
\end{aligned}
$$

[ ] は $\frac{1}{\chi(\sigma)} \ln \frac{\sigma-\alpha}{\sigma-\xi}$ を表わし, 肩の+, 一は, 境界上 で領域+，一側から近づいたときの値を示す. 式 $(\mathrm{A} \cdot 1)$ の右辺の項は, 留数計算より

$$
\text { 右辺 }=\frac{1}{\chi(\sigma)} \ln \frac{\zeta-\alpha}{\zeta-\xi} \text {. }
$$

また，

$$
\begin{array}{ll}
{\left[\ln \frac{\sigma-\alpha}{\sigma-\xi}\right]^{-}=\left[\ln \frac{\sigma-\alpha}{\sigma-\xi}\right]^{+}-2 \pi i} & \text { on } \widehat{\xi \alpha} \cdots \cdot(\mathrm{A} \cdot 3) \\
\chi^{-}(\sigma)=\chi^{+}(\sigma) e^{-2 \pi i \lambda}=-\frac{\chi^{+}(\sigma)}{\chi} & \text { on } \widehat{\alpha \beta} \cdots \cdot(\mathrm{A} \cdot 4)
\end{array}
$$

を用いて, 式 $(\mathrm{A} \cdot 1)$ の左辺を+の側の積分に変換し, 整理すると,

$$
\begin{aligned}
& \frac{1}{2 \pi i} \int_{\alpha}^{\beta} \ln \frac{\sigma-\alpha}{\sigma-\xi} \frac{d \sigma}{\chi(\sigma)(\sigma-\zeta)} \\
& =\frac{1}{1+\chi}\left[\frac{1}{\chi(\zeta)} \ln \frac{\zeta-\alpha}{\zeta-\xi}-\int_{\xi}^{\alpha} \frac{d \sigma}{\chi(\sigma)(\sigma-\zeta)}\right] \cdots \cdots(\mathrm{A} \cdot 5)
\end{aligned}
$$

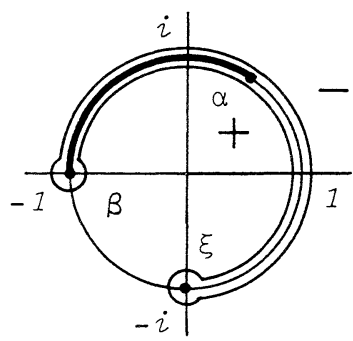

Fig. 8 Contour integral.

Table 2 Nondimensional stress intensity factors under a concentrated torsional moment.

\begin{tabular}{|c|ccc|ccc|}
\hline & \multicolumn{3}{|c|}{$F_{B}$} & \multicolumn{3}{c|}{$F_{S}$} \\
\cline { 2 - 7 }$c / W$ & $v=0.0$ & $\nu=0.25$ & $\nu=0.5$ & $v=0.0$ & $v=0.25$ & $v=0.5$ \\
\hline 0.010 & -0.539 & -0.580 & -0.587 & 0.078 & -0.074 & -0.272 \\
0.025 & -0.547 & -0.610 & -0.663 & 0.230 & 0.121 & -0.030 \\
0.050 & -0.537 & -0.609 & -0.683 & 0.359 & 0.282 & 0.172 \\
0.100 & -0.508 & -0.581 & -0.665 & 0.512 & 0.463 & 0.393 \\
0.200 & -0.452 & -0.517 & -0.595 & 0.705 & 0.680 & 0.644 \\
0.300 & -0.397 & -0.452 & -0.518 & 0.837 & 0.820 & 0.797 \\
0.400 & -0.346 & -0.390 & -0.442 & 0.929 & 0.914 & 0.895 \\
0.500 & -0.299 & -0.332 & -0.371 & 0.984 & 0.968 & 0.948 \\
0.600 & -0.258 & -0.281 & -0.309 & 1.005 & 0.986 & 0.963 \\
0.700 & -0.225 & -0.240 & -0.263 & 0.995 & 0.974 & 0.948 \\
0.800 & -0.201 & -0.212 & -0.235 & 0.965 & 0.943 & 0.916 \\
0.900 & -0.186 & -0.198 & -0.224 & 0.925 & 0.905 & 0.883 \\
0.950 & -0.180 & -0.195 & -0.222 & 0.905 & 0.887 & 0.870 \\
\hline
\end{tabular}


上式を式（16）に代入すると

$$
H(\zeta)=-\frac{\left(M_{0}-i T_{0}\right) \chi(\zeta)}{2 \pi x D(1-\nu)} \int_{\xi}^{\alpha} \frac{d \sigma}{\chi(\sigma)(\sigma-\zeta)}
$$

となる.

次に，式 $(\mathrm{A} \cdot 6)$ の 1 次導関数を求める. まず，一般 の積分範囲として，次式を考える.

$$
F(\zeta)=\chi(\zeta) \int_{a}^{b} \frac{d \sigma}{\chi(\sigma)(\sigma-\zeta)}
$$

次式の $y(\zeta)$ を導入する.

$$
y(\zeta)=\frac{(\zeta-\alpha)(\zeta-\beta)}{\chi(\zeta)}
$$

ここで, 次の微分を考える.

$$
\frac{d}{d \sigma}\left[\frac{\frac{1}{y(\sigma)}}{\sigma-\zeta}\right]=\frac{\left[\frac{1}{y(\sigma)}\right]^{\prime}}{\sigma-\zeta}-\frac{\frac{1}{y(\sigma)}}{(\sigma-\zeta)^{2}}
$$

上式に $d \sigma$ を乗じ， $a$ から $b$ まで積分すると,

式 (A.9) 左辺

$$
=\left[\frac{\frac{1}{y(\sigma)}}{\sigma-\zeta}\right]_{a}^{b}=\frac{\frac{1}{y(b)}}{b-\zeta}-\frac{\frac{1}{y(a)}}{a-\zeta} \equiv g_{1}(\zeta)
$$

式 $(\mathrm{A} \cdot 9)$ 右辺

$$
=\{\beta+\lambda(\alpha-\beta)-\zeta\} f(\zeta)-(\zeta-\alpha)(\zeta-\beta) f^{\prime}(\zeta)
$$

ここで,

$$
f(\zeta)=\int_{a}^{b} \frac{d \sigma}{\chi(\sigma)(\sigma-\zeta)}, \quad f^{\prime}(\zeta)=\int_{a}^{b} \frac{d \sigma}{\chi(\sigma)(\sigma-\zeta)^{2}}
$$

とおいている. 式 $(\mathrm{A} \cdot 10,11)$ より,

$$
f^{\prime}(\zeta)+S(\zeta) f(\zeta)+T(\zeta)=0
$$

の微分方程式となる.ここで，

$$
\begin{aligned}
& S(\zeta)=\frac{1-\lambda}{\zeta-\alpha}+\frac{\lambda}{\zeta-\beta} . \\
& T(\zeta)=\frac{g_{1}(\zeta)}{(\zeta-\alpha)(\zeta-\beta)} .
\end{aligned}
$$

である.

$$
\text { 式 }(\mathrm{A} \cdot 13) \text { の一般解は, }
$$$$
\exp \left[\int S(\zeta) d \zeta\right] f(\zeta)+\int T(\zeta) \exp \left[\int S(\zeta) d \zeta\right] d \zeta
$$$$
=\text { Const }
$$

となり，また，上式中の $\exp$ の項は，式 $(\mathrm{A} \cdot 14)$ を用 いて,

$$
\exp \left[\int S(\zeta) d \zeta\right]=C_{1} \chi(\zeta)
$$

となる. $C_{1}$ は定数である. しかし, 式 $(\mathrm{A} ・ 16)$ の左辺 第 2 項の積分は求められないが, 式 $(A \cdot 16)$ に式 $(A \cdot 17)$ を代入し， 1 階微分すると，

$$
\frac{d}{d \zeta}\left[C_{1} \chi(\zeta) f(\zeta)\right]+C_{1} T(\zeta) \chi(\zeta)=0
$$

$$
F^{\prime}(\zeta)=-T(\zeta) \chi(\zeta)=-y(\zeta) g_{1}(\zeta)
$$

亡求まる. $a=\xi, b=\alpha$ のとき, 式 $(\mathrm{A} \cdot 19)$ は

$$
F^{\prime}(\zeta)=\frac{\chi(\zeta)}{\chi(\xi)} \frac{(\xi-\alpha)(\xi-\beta)}{(\xi-\zeta)(\zeta-\alpha)(\zeta-\beta)}
$$

となる. したがって, 式 $(A \cdot 6)$ の 1 階微分 $H^{\prime}(\zeta)$ が求 められた。

\section{参 考 文 献}

1) Hasebe, N. : Mixed boundary value problem of plate with crack, ASCE, J. of Engng. Mech., Vol.110, No. 1, pp. 37 48, 1984.

2) Tada, H. : The Stress Analysis of Cracks Handbook, Del Reserch Corporation, Pennsylvania, 1973.

3) Sih, G.C. : Handbook of Stress Intensity Factors, Lehigh University, Pennsylvania, 1973.

4) Murakami, Y. et al. : Stress Intensity Factors Handbook, Pergamon Press, Oxford, 1987.

5) Hasebe, N. : Bending of strip with semi-elliptic notches or cracks, ASCE, J. of Engng. Mech., Vol. 104, No. 6, pp. 1433 1450, 1978.

6) Hasebe, N. and Takemura, M. : Cracks occuring at a joint of a strip and a semi-infinite plate under out of plane load, Theoretical and Applied Mechanics, Vol. 29, Univ. Tokyo Press, 1981.

7) Hasebe, N., Matuura, S. and Kondo, N. : Stress analysis of a strip with a step and a crack, Engineering Fracture Mechanics, Vol.20, No. 3, pp. $447 \sim 462$, 1984.

8) Hasebe, N. and Miura, M. : Stress analysis of crack at an end of partly embedded strip, Proc. of Japan Society of Civil Engineers Structural Eng. / Earthquake Eng., Vol. 2, pp. 345s $\sim 352 s, 1985$.

9) Hasebe, N. and Inohara, S. : Stress analysis of a semi-infinite plate with an oblique edge crack, Ingenieur Archiv, Vol. 48, pp.129 141, 1980.

10) Hasebe, N., Miwa, M. and Nakamura, T. : Stress analysis of a crack at a juncture of a strip and a halfplane, Engineering Fracture Mechanics, pp. 225 236, 1989.

11）長谷部宣男・三浦雅彦：埋め込まれた板の埋め込み端の 両側から発生したクラック, 日本機械学会論文集, 第 47 巻, 第 423 号, pp. 1129 1136, 1981.

12) Savin, G. N. : Stress concentration arround holes, Chap. VI, Pergamon Press, 1961.

13) Williams, M. L. : Surface stress singularities resulting from various boundary conditions in angular corner of plate bending, 1st U.S. National Congress Applied Mechanics, McGraw-Hill Book Co. Inc., New York, Y. N., pp. 325 329, 1952.

14) Ishida, N. : Plates and Shells with cracks, ed. G. C. Sih, Chap.1, Noordhoff, Amsterdam, 1977.

(1989.11.25 • 受付)

さらに，式 $(\mathrm{A} \cdot 7,12)$ より上式は 